\title{
Comparative analysis of humoral immune responses and pathologies of BALB/C and C57BL/6 wildtype mice experimentally infected with a highly virulent Rodentibacter pneumotropicus (Pasteurella pneumotropica) strain
}

Juliane Fornefett ${ }^{1}$, Jaqueline Krause ${ }^{2}$, Kristin Klose ${ }^{3}$, Felix Fingas ${ }^{4,5}$, Rayk Hassert ${ }^{5}$, Laurentiu Benga ${ }^{6}$, Thomas Grunwald ${ }^{2}$, Uwe Müller ${ }^{7}$, Wieland Schrödl ${ }^{1}$ and Christoph Georg Baums ${ }^{1 *}$ (D)

\begin{abstract}
Background: Mice are a natural host for Rodentibacter (R.) pneumotropicus. Despite specific monitoring, it is still one of the most important infectious agents in laboratory animals. The objective of this study was to determine the virulence of a prevalent pathotype of $R$. pneumotropicus and characterize the host response in a new animal model.

Results: Intranasal infection of C57BL/6 and BALB/C mice with a R. pneumotropicus strain (JF4Ni) bearing the genes of the three known repeats in toxin (RTX) toxins resulted in an unprecedented high mortality and morbidity above 50 and $80 \%$, respectively. Morbidity was associated with severe weight loss as well as conjunctivitis and dyspnea. A main pathology was a catarrhal purulent to necrotic bronchopneumonia. Specific immune globuline (Ig) A was detected in tracheonasal lavages of most surviving mice which were still colonized by $R$. pneumotropicus. Furthermore, all surviving animals showed a distinct production of IgG antibodies. To differentiate T-helper cell (Th) 1 and Th2 immune responses we used subclasses of lgGs as indicators. Mean ratios of lgG2b to lgG1 were below 0. 8 in sera drawn from both mice strains prior infection and from BALB/c mice post infection. In contrast, C57BL/6 mice had a mean $\mathrm{lgG}$ b/lgG1 ratio of 1.6 post infection indicating a Th1 immune response in C57BL/6 versus a Th2 response in BALB/C mice associated with a tenfold higher bacterial load in the lung. In accordance with a Th1 response high antigen-specific lgG2C titers were detected in the majority of surviving C57BL/6 mice.
\end{abstract}

Conclusions: $R$. pneumotropicus JF4Ni is a highly virulent strain causing severe pneumonia and septicemia after intranasal infection of C57BL/6 and BALB/c mice. Persisting infections in the two mice strains are associated with Th1 and Th2 immune responses, respectively, and differences in the bacterial burden of the lung. The described model is ideally suited for future vaccination studies using the natural host.

Keywords: Bronchopneumonia, RTX toxins, Th1/Th2 responses, Colonization, Animal model

\footnotetext{
*Correspondence: christoph.baums@vetmed.uni-leipzig.de

'Institute for Bacteriology and Mycology, Faculty of Veterinary Medicine,

University Leipzig, An den Tierkliniken 29, 04103 Leipzig, Germany

Full list of author information is available at the end of the article
}

(c) The Author(s). 2018 Open Access This article is distributed under the terms of the Creative Commons Attribution 4.0 International License (http://creativecommons.org/licenses/by/4.0/), which permits unrestricted use, distribution, and reproduction in any medium, provided you give appropriate credit to the original author(s) and the source, provide a link to the Creative Commons license, and indicate if changes were made. The Creative Commons Public Domain Dedication waiver (http://creativecommons.org/publicdomain/zero/1.0/) applies to the data made available in this article, unless otherwise stated. 


\section{Background}

Pasteurella (P.) pneumotropica was thought to be a species occurring mainly in two different biotypes: Jawetz and Heyl $[1,2]$. However, $P$. pneumotropica was very recently reclassified and these two biotypes belong now to two different species, namely Rodentibacter $(R$.$) pneumotropicus and R$. heylii, respectively [3]. The differentiation of the two biotypes is based on the phenotype of the colony colour (grey and yellow, respectively), but polymerase chain reaction (PCR)-based differentiation is also possible [4-6]. In a recent study [7] differences in distribution of virulence factors between the two biotypes are described. Three different repeats-in-toxin (RTX) toxins, designated PnxI, PnxII and PnxIII, have been identified in $P$. pneumotropica. Whilst PnxI and PnxII are secreted and act as haemolysins or cytotoxins [8], PnxIII is associated with the bacterial membrane. Specifically, PnxIII interacts with the extracellular matrix $[9,10]$ but can also induce host cell cytotoxicity $[9,10]$. Therefore, these RTX toxins are considered as important virulence factors [9].

$P$. pneumotropica is among the most important pathogens in laboratory animal populations with a reported prevalence of 4 to $13 \%$ in Europe and North America, respectively [11]. It is described as an opportunistic pathogen with low virulence in immunocompetent mice [2] but clinical signs were recorded in immunodeficient and -suppressed mice or in co-infections with Mycoplasma pulmonis [12] or Pneumocystis carinii [13]. Infected animals are generally unsuitable for scientific research due to suppurative to necrotizing lesions in various organs [14] and modulation of the immune response [15]. The Federation of Laboratory Animal Science Association (FELASA) lists P. pneumotropica as an important pathogen in mice, rats and hamsters and recommends the examination every 3 months [16]. Various monitoring methods are described including PCR $[4,5,17]$ and indirect enzyme-linked immunosorbent assays (ELISAs) [18-20].

It is common practice to use soiled bedding sentinels for health monitoring of laboratory animals. Nevertheless, studies revealed a limited survival of $P$. pneumotropica in the environment $[21,22]$ and the failure of detecting $P$. pneumotropica infections by bedding sentinels [23].

In this study, we evaluated the pathologies and immune responses induced by experimental infection of BALB/c and C57BL/6 mice with a $R$. pneumotropicus pathotype emerging in German laboratory animal facilities. The new intranasal model leading to severe pneumonia, septicaemia but also to persisting infections is important for future studies on virulence and protection.

\section{Results \\ Distribution of pnxIA, pnxIIA and pnxIIIA in $R$. pneumotropicus and $R$. heylii}

Different genes encoding RTX-toxins have been identified in $P$. pneumotropica, namely pnxIA, pnxIIA and $p n x$ IIIA. By PCRs targeting these $p n x$ genes, we investigated recently collected $27 R$. pneumotropicus and $26 R$. heylii strains. This profiling revealed that the distribution of pnxIA, $p n x$ IIA and pnxIIIA differs substantially between the two species (Table 1 ). In $46 \%$ of the $R$. heylii strains only $p n x \mathrm{I}$ was detected. The gene $p n x \mathrm{II}$ was not found at all in this species. Twelve percent of the $R$. heylii strains carried both pnxIII and pnxI, whereas $43 \%$ were PCR negative for all RTX genes. In contrast, all three RTX genes were found in $74 \%$ of the $R$. pneumotropicus strains. Only $7 \%$ of the $R$. pneumotropicus strains did not carry any of the $p n x$ genes. For further investigation, a recently isolated $p n x \mathrm{IA}+, p n x \mathrm{IIA}+$ and $p n x \mathrm{IIIA}$ $+R$. pneumotropicus strain (JF4Ni) was chosen, because of its prevalent genotype identified by the screening of strains collected in Germany.

\section{Morbidity, mortality and histopathology of experimentally infected animals and sentinels}

Intranasal infection with $10^{8} \mathrm{CFU} R$. pneumotropicus JF4Ni resulted in 100\% (16/16) morbidity in BALB/c and 87.5\% (14/16) morbidity in C57BL/6 mice within one day. Fifty-six percent (9/16) of BALB/c died or had to be euthanized within 2-4 days after infection and 50\% (8/ 16) of C57BL/6 within 3-6 days after infection (Fig. 1a). Diseased mice showed unspecific signs such as ruffled coat, bended back, heavy weight loss (Fig. 1b), dehydration as well as specific signs such as dyspnoea, conjunctivitis and mild incoordination in two cases. Significant differences in mortality and morbidity were only recorded between infection animals and controls, but not between the two mouse strains. All early deceased mice showed multifocal moderate to severe catarrhal-purulent bronchopneumonia, in some cases with necrosis (Table 2 and Fig. 1c). These pathologies were not recorded in mice which survived the experimental $R$. pneumotropicus infection. A mild to moderate interstitial pneumonia was found in all mice including controls and sentinels.

Table 1 Distribution of RTX genes pnxIA, pnxIIA and pnxIIIA in R. pneumotropicus and R. heylii

\begin{tabular}{|c|c|c|c|c|c|c|c|c|}
\hline & only pnxlA & only pnx\|A & only pnxIIIA & $p n x \mid A+\| A$ & $p n x \mid A+I I I A$ & $p n x\|A+\| A$ & $p n x \mid A+\|A+I\| l a$ & none \\
\hline R. pneumotropicus $(n=27)$ & $7 \%$ & $0 \%$ & $0 \%$ & $4 \%$ & $4 \%$ & $4 \%$ & $74 \%$ & $7 \%$ \\
\hline R. heylii $(n=26)$ & $46 \%$ & $0 \%$ & $0 \%$ & $0 \%$ & $12 \%$ & $0 \%$ & $0 \%$ & $42 \%$ \\
\hline in total $(n=53)$ & $26 \%$ & $0 \%$ & $0 \%$ & $2 \%$ & $8 \%$ & $2 \%$ & $38 \%$ & $24 \%$ \\
\hline
\end{tabular}




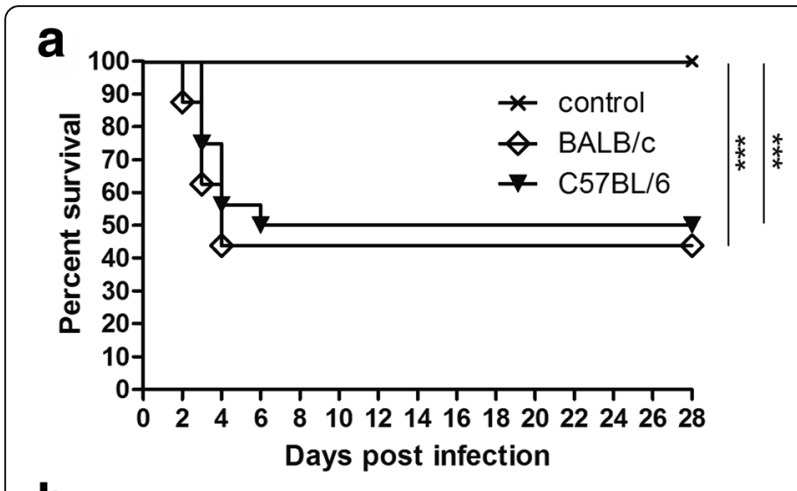

b

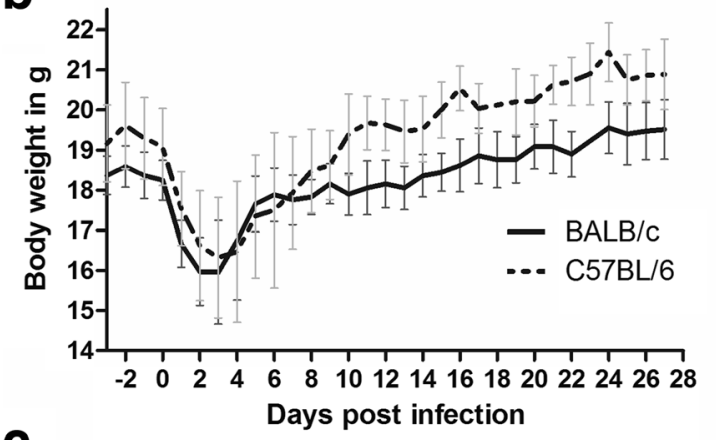

C

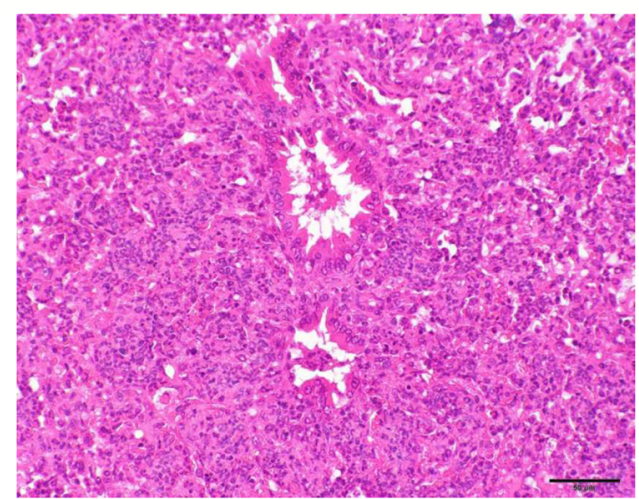

Fig. 1 Mortality (a) and body weight (b) of the indicated mice infected with R. pneumotropicus JF4Ni ( $n=16$ per mouse strain) or treated with PBS as control ( $n=10$ for BALB/C and $n=9$ for C57BL/ 6 , one control died during anaesthesia). Data of contact sentinels are not included. Bronchopneumonia was a main pathology. A multifocal severe catarrhal-purulent bronchopneumonia of a BALB/C mouse 2 days after intranasal infection is shown (c). Alveoli and bronchioles of this mouse were infiltrated with high numbers of neutrophilic granulocytes (200 x magnification). The log rank test was used to analyse differences between the two mice strains and the groups (a)

Contact and bedding sentinels showed no clinical signs and pathologies related to $R$. pneumotropicus infection (data not shown).

\section{Detection of $R$. pneumotropicus in tracheonasal lavages (TNL) and internal organs}

R. pneumotropicus was detected in TNL and various internal organs of experimentally infected animals.
Table 2 Degree and extent of catarrhal-purulent

bronchopneumonia in R. pneumotropicus infected mice (for definition of scores see Additional file 5: Table S5)

\begin{tabular}{lllllllll}
\hline & \multicolumn{3}{l}{ BALB/C } & & & \multicolumn{2}{l}{ C57BL/6 } \\
\cline { 2 - 3 } & 0 & $1-3$ & $4-7$ & & 0 & $1-3$ & $4-7$ \\
\hline Controls & $10 / 10$ & $0 / 10$ & $0 / 10$ & & $9 / 9$ & $0 / 9$ & $0 / 9$ \\
Losses & $0 / 9$ & $1 / 9$ & $8 / 9$ & & $1 / 8$ & $0 / 8$ & $7 / 8$ \\
Survivors & $7 / 7$ & $0 / 7$ & $0 / 7$ & & $8 / 8$ & $0 / 8$ & $0 / 8$ \\
Contact sentinels & $4 / 4$ & $0 / 4$ & $0 / 4$ & & $4 / 4$ & $0 / 4$ & $0 / 4$ \\
\hline
\end{tabular}

Furthermore, this pathogen disseminated into non-respiratory internal organs in every experimentally infected mouse (Fig. 2). Bacterial loads in the brains, lungs, $\mathrm{L} \mathrm{n}$. tracheobronchiales, livers, spleens, kidneys and genito-urinary tracts were significantly higher in BALB/c than in C57BL/6 mice as assessed by semi-quantitative scoring (mean bacteriological scores for mice succumbing to infection: BALB/c: 11.6 with SD 3.0 and C57BL/6: 6.1 with SD 1.9; $p=0.002$; Additional file 1: Table S1; Fig. 2). In contact sentinels $R$. pneumotropicus was mainly detected in the lungs and TNLs (Fig. 2), indicating that dissemination occurred mainly in experimentally infected animals but not in contact sentinels. Additionally, R. pneumotropicus was not detected in bedding sentinels at all.

$\mathrm{BALB} / \mathrm{c}$ and $\mathrm{C} 57 \mathrm{BL} / 6$ mice succumbing to infection within 2 to 6 days post infection (dpi) had high specific bacterial loads in TNL in most cases (mean of $2.6 \times 10^{6}$ colony forming units $(\mathrm{CFU}) / \mathrm{ml}$ with SD $3.1 \times 10^{6}$ and $3.4 \times 10^{5} \mathrm{CFU} / \mathrm{ml}$ with SD $3.7 \times 10^{5}$, respectively). At the end of the observation period, the bacterial load of the lung was significantly higher in surviving BALB/c mice than in C57BL/6 mice (mean of $4.4 \times 10^{4} \mathrm{CFU}$ per $\mathrm{g}$ tissue with SD $3.2 \times 10^{4}$ and mean of $3.9 \times 10^{3}$ CFU per g tissue with SD $5.0 \times 10^{3}$, respectively, Fig. $3 \mathrm{a}$ ). In contact sentinels, mean $R$. pneumotropicus loads in TNL of $2.8 \times 10^{4} \mathrm{CFU}$ per $\mathrm{ml}$ TNL in BALB/c and $2.6 \times 10^{4} \mathrm{CFU}$ per $\mathrm{ml}$ TNL in C57BL/6 were recorded (SD $3.9 \times 10^{4}$ and $1.9 \times 10^{4}$, respectively). Noteworthy, the mean bacteriological score based on semi-quantitative assessment of bacterial loads in the brains, lungs, lymphonodi tracheobronchiales, livers, spleens, kidneys and genito-urinary tracts was significantly higher in surviving BALB/c than in surviving C57BL/6 mice (mean bacteriological scores of 5.7 (SD 2.7) and 2.4 (SD 3.4) in BALB/c and C57BL/6 mice, respectively; $p=0.036$; Additional file 2: Table S2; Fig. 2).

\section{Antigen-specific $\lg A$ in TNL of experimentally infected animals and sentinels}

As $R$. pneumotropicus was isolated in TNL of experimentally infected mice surviving to the end of the observation period, we asked if this colonization occurred in the presence of specific IgA. $R$. pneumotropicus-specific IgA was not detected in TNL of controls and mice that 


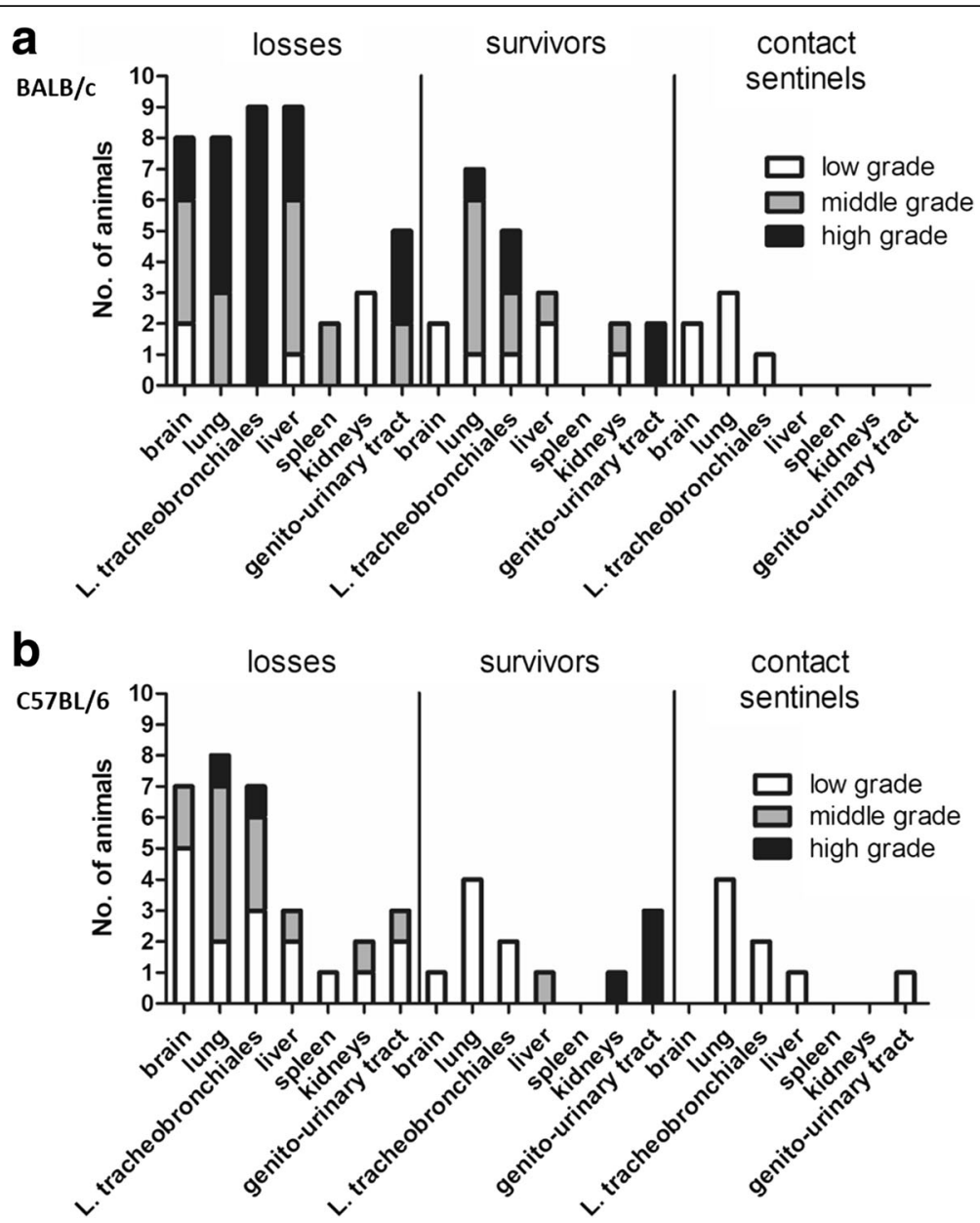

Fig. 2 Semi-quantitative determination of R. pneumotropicus in the indicated tissues of BALB/C (a) and C57BL/6 (b) mice either infected experimentally (losses and survivors) or used as contact sentinels. Losses occured 2-6 dpi, survivors were sampled 28 dpi and contact sentinels 56 dpi. A low grade is equal to less than 20 CFU per plate; a middle grade refers to 20-70 CFU and a high grade to more than 70 CFU per plate

died within 6 days following experimental infection. On the other hand, TNLs collected 4 weeks post infection from experimentally infected mice of both strains and $\mathrm{BALB} / \mathrm{c}$ contact sentinels revealed mean titers above 80 ELISA units and mainly positive IgA-titers against $R$. pneumotropicus (Fig. 3b). In contrast, C57BL/6 contact sentinels had rather low specific IgA titers (mean titer of 8 ELISA units with a SD of 5.9). In summary P. pneumotropicus was found to colonize efficiently respiratory mucosa despite the presence of specific IgA in mice surviving experimental infection.

\section{Serum IgG-levels in experimentally infected animals and sentinels}

Experimental infection of BALB/c and C57BL/6 mice elicited specific IgG-titers in all surviving animals (sampled $28 \mathrm{dpi}$ ) as well as in contact sentinels (sampled $56 \mathrm{dpi}$ ) as shown by ELISA using whole cell extract or a concentrated culture supernatant as antigen (Fig. 4a and b). Sera collected prior to infection $(n=59)$ and from control animals $(n=19)$ consistently gave negative results. Furthermore, $R$. pneumotropicus-specific IgG was not recorded in sera from mice succumbing to infection within the first $6 \mathrm{dpi}$ or in sera from bedding sentinels.

\section{IgG subclass differentiation indicate differences in the immune response of $\mathrm{BALB} / \mathrm{C}$ and $\mathrm{C} 57 \mathrm{BL} / 6$ mice to $R$. pneumotropicus infection}

As the specific bacterial load of the lung of surviving $\mathrm{BALB} / \mathrm{c}$ mice was significantly higher than the load of C57BL/6 mice (Fig. 3a), we investigated putative differences in the immune response of the two mice strains. We used levels of IgG subclasses as indicators for the kind of immune response as IgG2a and IgG2b are associated with a Th1 response while IgG1 is associated with a Th2 response. Upon infection, not only the ratio of antigen-specific IgG subtypes might change in serum in association with a Th1 or Th2 response, but also the overall ratios of IgG subtypes [24]. Differentiation of IgG subclasses was conducted in $7 \mathrm{BALB} / \mathrm{c}$ and $8 \mathrm{C} 57 \mathrm{BL} / 6$ 

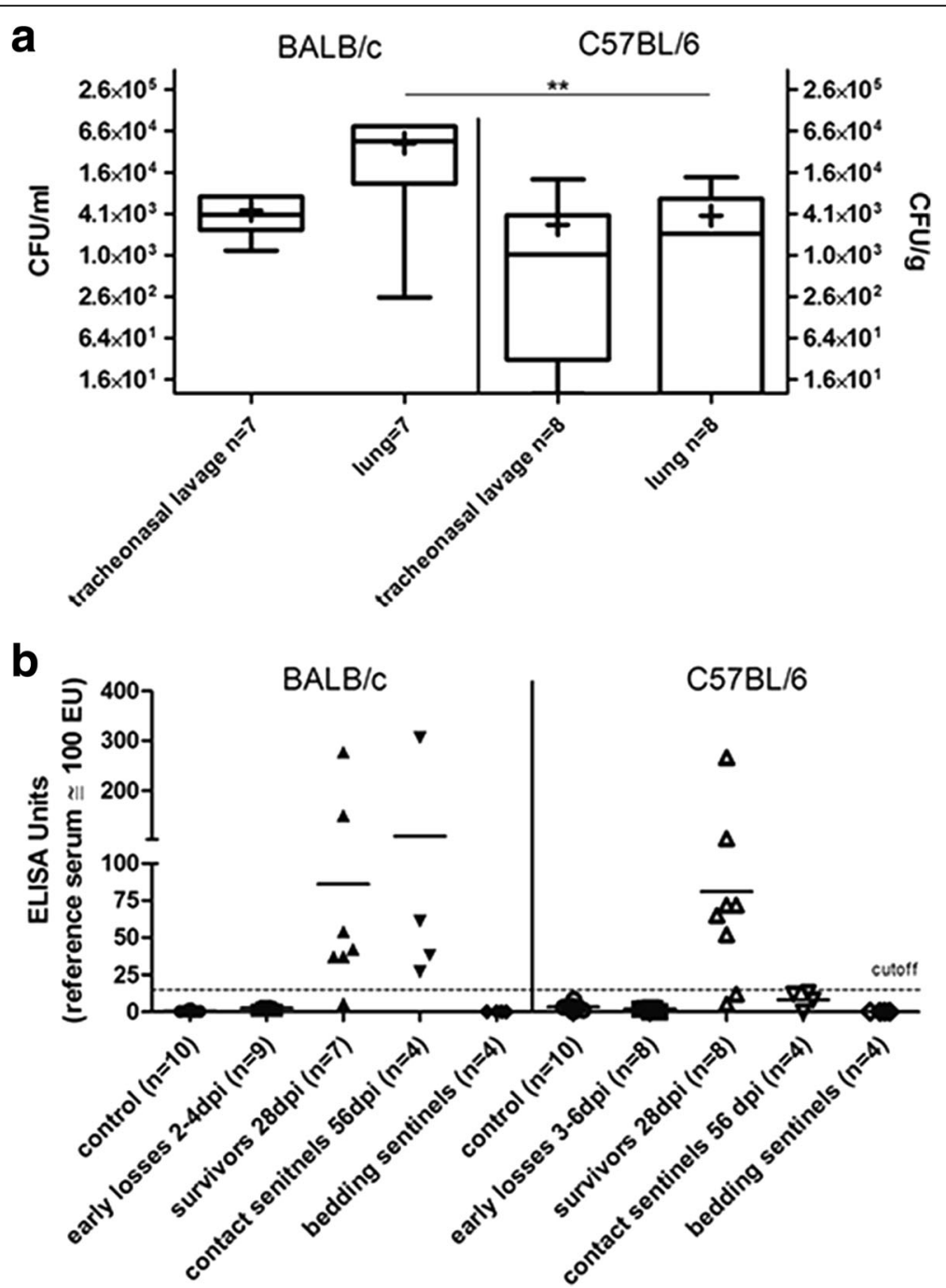

Fig. 3 Quantitative determination of R. pneumotropicus in TNL and lungs of the indicated mice surviving experimental infection (a) and pathogen-specific lgA-levels in TNL (b). Medians are marked by the horizontal line. The non-parametric Mann-Whitney test was used for statistical analysis (** for $P \leq 0.01$ )

mice showing a distinct antibody response to $R$. pneumotropicus antigen. In BALB/c mice, we measured the ratios of IgG2a to IgG1 and IgG2b to IgG1. Due to the lack of IgG2a in C57BL/6 mice [25] only the ratio of IgG1 to IgG2 in was determined in this strain. Prior to infection, the mean $\operatorname{IgG} / \operatorname{IgG} 1$ ratios were 0.5 for IgG2a and 0.4 for IgG2b in BALB/c and 0.8 for IgG2b in C57BL/6 mice (Fig. 5a and b). Post infection, the mean IgG2a/IgG1 ratio in BALB/c mice increased slightly to 0.7 , while the IgG2b/IgG1 ratio remained constant. These results indicate a balanced immune response with a tendency to Th2 in BALB/c mice. In C57BL/6 the IgG2b to IgG1 ratio increased to 1.6 indicating a Th1 prone immune response (Fig. 5a). Accordingly, the majority of surviving, experimentally infected C57BL/6 mice had high $R$. pneumotropicus-specific
IgG2c titers (above 50 ELISA Units), whereas these antibodies were not recorded in sera drawn from these mice prior infection or from control mice (Fig. 5c).

\section{Discussion}

Experimental infections with $P$. pneumotropica have been conducted in vaccination studies to investigate the protective efficacies of different recombinant proteins such as the RTX toxin PnxIII [9] and different outer membrane proteins [26]. In these studies, protective efficacies were assessed by determining specific bacterial loads at different mucosal sites such as the nasal conchae, lung and conjunctivae. However, clinical read out parameters were not included. Here, an infection model with high rates of morbidity and mortality in immunocompetent $\mathrm{BALB} / \mathrm{c}$ and $\mathrm{C} 57 \mathrm{BL} / 6$ wildtype mice was 


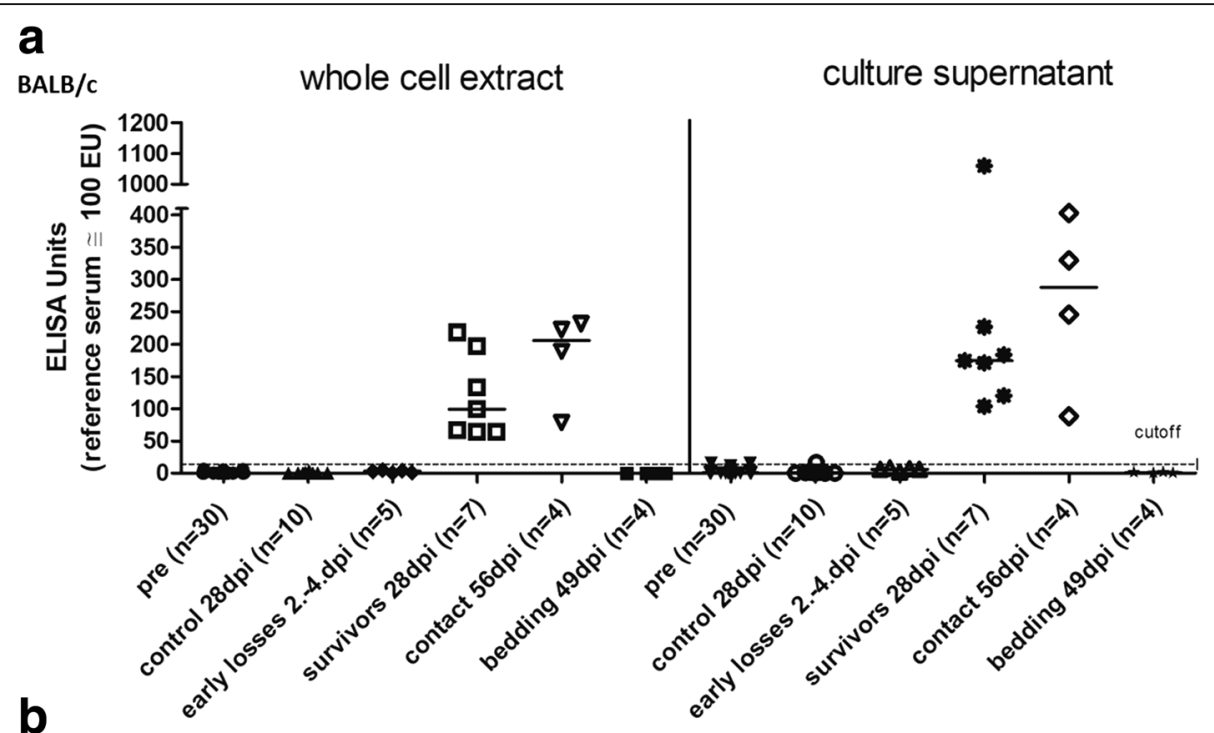

C57BL/6

whole cell extract

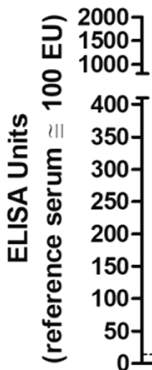

culture supernatant
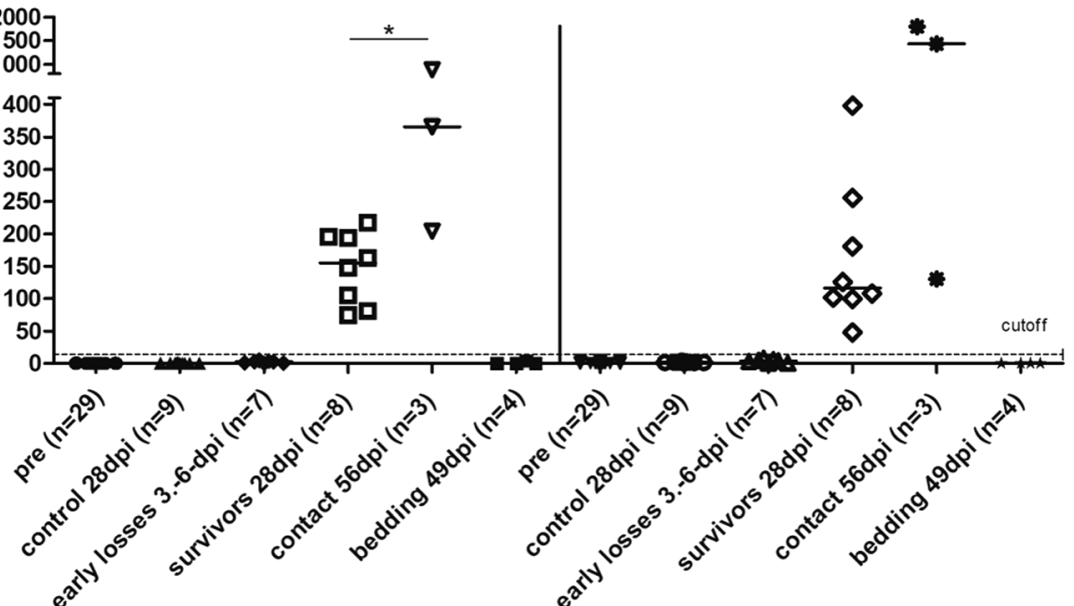

Fig. $4 \mathrm{lgG}$-levels against the indicated R. pneumotropicus antigens in intranasally infected BALB/C (a) and C57BL/6 (b) mice and the respective contact and bedding sentinels in sera drawn at the indicated time points. A serum pool from mice naturally infected with $R$. pneumotropicus was used as reference serum. The culture supernatant had a concentration factor of 100. Early losses refer to mice killed for animal welfare reasons after developing severe signs of sepsis. Statistical analysis with the Mann-Whitney test was performed to analyse differences between the different groups. The Wilcoxon test was used to compare different time point values within the same groups. The star in panel (b) (whole cell extract) indicates significance ${ }^{*}$ for $P \leq 0.05$ )

established for the first time, enabling the usages of respective read out parameters in future vaccination studies. The high morbidity was associated with severe lung pathologies and dissemination of $R$. pneumotropicus to extra-respiratory sites such as liver and brain. Based on the presented data we consider these models as ideal for investigating protection against severe pneumonia and associated sepsis. Importantly, numerous immunogens of $R$. pneumotropicus are homologous to proteins expressed by Haemophilus influenza [26] and P. multocida [26], two important pneumonia and sepsis agents in humans and livestock, respectively. Thus, vaccination trials using the described murine models might be relevant for these pathogens as well. The fact that mice are the natural host of $R$. pneumotropicus is an important advantage, especially as members of the Pasteurellaceae show substantial host adaptation.

The infection dose of $1 \times 10^{8} \mathrm{CFU}$ used in this study is high. However, previous studies have used similar or even higher $[15,27,28]$ doses without induction of morbidity and mortality. For example, Chapes et al. could not induce any clinical signs or pathologies in immunocompetent C57BL/6 wildtype mice with a 400 times higher dose of the $R$. pneumotropicus type strain ATCC 35149 [27]. Furthermore, immunocompetent Crlj:CD1 mice did not develop lung lesions or clinical signs of disease 


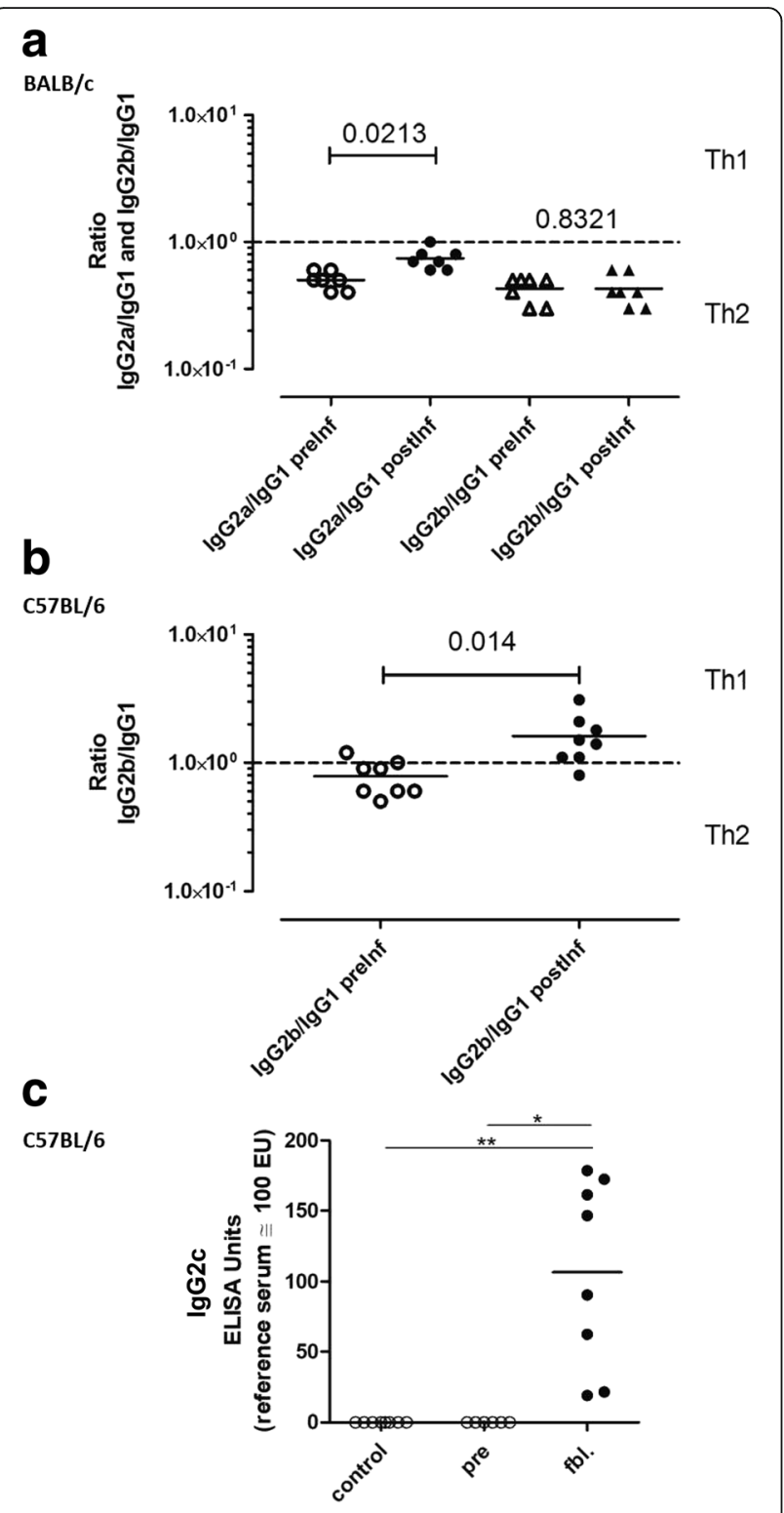

Fig. 5 Ratios of the indicated lgG-subclasses in surviving C57BL/6 (a) and $B A L B / C$ (b) mice and antigen-specific lgG2C titers in respective C57BL/6 (c). Seven infected BALB/C and 8 C57BL/6 mice with a distinct antibody answer to R. pneumotropicus antigen (Fig. 4) were chosen for the determination of lgG subclasses in (a) and (b), respectively. In BALB/C mice the ratios between lgG2a to lgG1 and $\lg G 2 \mathrm{~b}$ to $\lg \mathrm{G} 1$ were determined. As C57BL/6 mice lack IgG2a, only $\lg \mathrm{G} 1$ and $\lg \mathrm{G} 2 \mathrm{~b}$ were measured. Medians are marked by the horizontal line. Differentiation of a Th1 and Th2 immune response is indicated by the dashed line. lgG2c-titers in C57BL/6 mice against whole cell extract of $R$. pneumotropicus (c). Titers were determined as indicated either in experimentally infected survivors or respective controls (fbl $=$ final bleeding). A serum pool from C57BL/6 mice naturally infected with $R$. pneumotropicus was used as reference serum. The non-parametric MannWhitney test was used for statistical analysis. The $P$-values are indicated

after experimental infection with the $R$. pneumotropicus type strain in contrast to immunodeficient NOD/Shijicscid/Jcl mice [28]. This difference to previous studies might be related to differences in virulence between $R$. pneumotropicus strains. The $R$. pneumotropicus JF4Ni strain used in this study is regarded as highly virulent based on the results of the experimental infections and the substantial health issues of the animal facility it was detected in. The fact that this strain bears all three known RTX toxin genes of this pathogen might be related to its virulent phenotype as the toxins are considered important virulence factors [8-10]. Specifically, PnxIII is cytotoxic to macrophages [10], which are crucial for clearance of $R$. pneumotropicus in the lungs as shown by transfer of Toll-like receptor 4-positive macrophages to knockout mice [29]. Noteworthy, more than $70 \%$ of the $R$. pneumotropicus strains investigated in this study shared this RTX toxin genotype, namely pnxIA+ $p n x I I A+p n x I I I A+$. As these strains were recently isolated, putative emergence of this important pathotype should be further investigated.

All surviving animals of both mouse strains and their contact sentinels produced high levels of $R$. pneumotropicus-specific IgG antibodies, as shown by ELISA using two different antigens. Sera drawn prior to infection and from control animals consistently gave negative results which indicates high specificities of the established ELISAs. Noteworthy, a commercially available ELISA for the detection of P. pneumotropica-specific IgG failed to detect specific antibodies in the sera of infected animals surviving until the end of the experiment (results not shown).

In agreement to previous studies, all bedding sentinels were serologically negative, rendering this approach inappropriate for $R$. pneumotropicus health monitoring $[21,23]$. On the other hand, serological screenings of contact sentinels for $R$. pneumotropicus-specific serum IgG using the described ELISA seems to be rather sensitive as an indirect indicator of infection and specific based on the results shown in Fig. 4. Furthermore, contact sentinels might be useful to study clinically inapparent colonization, as none of these mice became morbid at any time post infection despite colonisation of the lungs in numerous animals (Fig. 2).

This study shows for the first time that $R$. pneumotropicus infection results in a mean ratio of IgG2b to IgG1 above 1 in C57BL/6 but not in BALB/c mice indicating a Th1-prone immune response. In contrast, IgG2/IgG1 in $\mathrm{BALB} / \mathrm{c}$ mice remained below 1 post infection suggesting a more balanced response. It is known already that BALB/ c and C57BL/6 mice exhibit distinct genetically determined differences in their immune systems under physiological conditions, which includes higher amounts of interleukin (IL)-12 in C57BL/6 [30] and associated higher productions of IgG2c and $2 \mathrm{~b}$ [31] inducing a Th1 immune response. However, based on the rapid progress of disease starting very early after infection, it is reasonable to hypothesize that other mechanisms but Th1 and Th2 
immune responses were crucial for survival in the immunologically naïve mice of the described experimental infection. This is in agreement with the finding that the more Th1-prone C57BL/6 and the more Th2-prone BALB/c mice show comparable morbidities and pathologies.

We found high titres of $R$. pneumotropicus-specific IgA (above 150 Elisa) in the TNL of two surviving $\mathrm{BALB} / \mathrm{c}$ mice $28 \mathrm{dpi}$ in association with high numbers of this pathogen (above $10^{4} \mathrm{CFU} / \mathrm{ml}$, results not shown). These results suggest maintenance of mucosal colonization of $R$. pneumotropicus despite high titers of specific IgA. As the specific bacterial load in the lung of the investigated survivors was significantly lower in C57BL/6 than in $\mathrm{BALB} / \mathrm{c}$ mice, it is reasonable to hypothesize that the putative Th1-prone immune response in C57BL/6 mice is more efficient in restricting persisting lung infection.

\section{Conclusions}

Many $R$. pneumotropicus strains recently isolated from laboratory mice in Germany carry the genes of the three known RTX toxins of this pathogen. Intranasal application of the pnxIA $+p n x \mathrm{IIA}+p n x \mathrm{IIIA}+R$. pneumotropicus JF4Ni strain results in invasive and fatal infections in wt $\mathrm{BALB} / \mathrm{c}$ and $\mathrm{C} 57 \mathrm{BL} / 6$ mice associated with severe pneumonia and dissemination to extra-respiratory sites. In contrast to $\mathrm{BALB} / \mathrm{c}$ mice, surviving $\mathrm{C} 57 \mathrm{BL} / 6$ mice show a Th1-prone immune response and a bacterial load of the lung below $10^{4} \mathrm{CFU}$ per $\mathrm{g}$ tissue after $28 \mathrm{dpi}$. The described model is ideal for future studies on virulence and protection elicited by vaccination.

\section{Methods}

\section{Animals}

Eight-week-old female wild type BALB/c mice obtained from Charles River laboratory (Sulzfeld Germany) and C57BL/6 mice from Janvier Labs (Le Genest-Saint-Isle France), both specific pathogen free, were caged randomly in 6 groups per strain including 2 uninfected and 4 infected groups. Each group contained 4 infection/ placebo treated animals and one contact sentinel. Additionally, 10 week old female P. pneumotropica-free CD1 outbred mice (raised by the Fraunhofer Institute for Cell Therapy and Immunology, Leipzig, Germany) were included in this study as bedding sentinels ( 2 cages with 4 mice each). Each bedding-group was assigned to one mouse strain. The number of animals included in this study was based on the objectives to reveal putative differences between BALB/c and C57BL/6 mice in susceptibility, to evaluate sentinel monitoring and to obtain convalescence sera for a further immunoproteomics study. All animals were housed as described in a previous study in detail [32], which included ventilated cages with HEPA filters and air conditioning as well as ad libitum feeding and drinking. One week before infection blood samples were collected from the submandibular vein and stored at $-20{ }^{\circ} \mathrm{C}$.

\section{Bacterial strains and culture media}

$R$. pneumotropicus and $R$. heylii were cultivated as appropriate overnight at $37{ }^{\circ} \mathrm{C}$ on Columbia Blood Agar $(\mathrm{COB})$ or in Brain Heart Infusion (BHI). Experimental infection was conducted with $R$. pneumotropicus strain JF4Ni grown in BHI until a concentration of $10^{8}$ colony forming units (CFU) per millilitre was reached. This strain was recently isolated from a German research facility with severe health problems associated with dyspnoea and increased mortality in $\mathrm{P} 2 \mathrm{X}_{2} / \mathrm{P}_{2} \mathrm{X}_{3}{ }^{\mathrm{Dbl}-/-}$ knockout but also wt mice [33]. Furthermore, $R$. pneumotropicus reference strain ATCC 35149 and 27 Biotype Jawetz- as well as 26 Biotype Heyl strains were included in this study (Additional file 3: Table S3).

\section{Infection}

For experimental infection/mock treatment mice were anaesthetised by isoflurane inhalation. Mice were experimentally infected by intranasal application of $1 \times 10^{8}$ CFU $R$. pneumotropicus JF4Ni in $25 \mu \mathrm{l}$ phosphate buffered saline (PBS, $12.5 \mu \mathrm{l}$ per nostril). Controls were inoculated with PBS only. Contact sentinels remained untreated, bedding sentinels were turned over to used bedding 7 days after inoculation. Experimentally infected and sentinel animals were sacrificed 4 and 8 weeks after experimental infection, respectively. For this, mice were anaesthesized through intraperitoneal application of $100 \mathrm{mg}$ ketamin per $\mathrm{kg}$ body weight and $5 \mathrm{mg}$ xylazin per $\mathrm{kg}$ body weight. They were bled by heart puncture and finally killed by cervical dislocation.

\section{Clinical examination and treatment}

Every $12 \mathrm{~h}$ thorough adspection and weighing of mice was performed. Based on predefined criteria (Additional file 4: Table S4) clinical signs were scored. Mice with a cumulative clinical score of 3 or more were treated with flunixin meglumine for animal welfare reasons $(5 \mathrm{mg}$ per $\mathrm{kg}$ body weight every $12 \mathrm{~h}$ subcutaneously). The following end points led to euthanasia of respective animals: bleeding from orifices, paralysis, acute respiratory distress, cyanosis and $20 \%$ weight loss. Mice with a cumulative score above or equal 9 or a score above or equal 6 for 24 h were also killed for animal welfare reasons.

\section{Pathological examinations}

For pathological studies brain, nasal conchae, lung, liver, spleen and kidney were collected, macroscopically examined and fixed in $4 \% \mathrm{CaCO}_{3}$ buffered formalin. Tissues were embedded in paraffin, sectioned and stained with haematoxylin and eosin for light microscopy. Scoring of 
histopathological findings was conducted as specified in Additional file 5: Table S5.

\section{Cultural examinations}

For semi quantitative cultural examinations, lung, brain, lymphonodi tracheobronchiales, liver, spleen, kidney and the genito-urinary tract of all $\mathrm{BALB} / \mathrm{c}$ and $\mathrm{C} 57 \mathrm{BL} / 6$ mice were collected and a fresh cut side was pressed on a $\mathrm{COB}$ plate, which was incubated for $24 \mathrm{~h}$ at $37^{\circ} \mathrm{C}$ after streaking. For comparative analysis low, middle and high grades of detection of the typical colonies were scored with 1, 2 and 3 for each investigated tissue, respectively. The sum of the scores for all investigated tissues constitutes the total bacteriological score of each animal. Furthermore, quantitative cultural examinations were performed with the TNLs $(300 \mu \mathrm{l}$ PBS). For this, TNLs were serially diluted, spread on $\mathrm{COB}$ in duplicates and incubated for $24 \mathrm{~h}$ at $37{ }^{\circ} \mathrm{C}$. Colonies were differentiated by MALDITOF-MS (Bruker microflex LT, Bremen).

\section{Antigen preparation and ELISA for detection of antigen- specific serum-lgG, serum-IgG2c and mucosal IgA} ELISAs were established for detection of serum IgG and mucosal IgA directed against $R$. pneumotropicus antigen. Either a whole cell extract or a concentrated culture supernatant of $R$. pneumotropicus JF4Ni was used as antigen.

For preparation of the antigens, $100 \mathrm{ml} R$. pneumotropicus culture were centrifuged at $2000 \mathrm{~g}$ for $15 \mathrm{~min}$ at $4{ }^{\circ} \mathrm{C}$. The supernatant was concentrated 100 fold with a $30 \mathrm{kDa}$ centrifugal filter unit (Amicon ultra), mixed with $0.5 \mathrm{ml} 10 \mathrm{x}$ protease inhibitor (Protease Inhibitor Cocktail with EDTA by Sigma Aldrich) per g cell pellet and dialyzed against $0.9 \% \mathrm{NaCl}$.

Whole cell extract was prepared from pelleted bacteria as described for Streptobacillus moniliformis previously [32]. Three hundred nanogramms of $P$. pneumotropica antigen (either whole cell extract or a concentrated culture supernatant) or casein (background measurement) were used per well to coat Corning Costar assay plates in carbonate buffer ( $\mathrm{pH}$ 8.1). Blocking with casein and washing of ELISA plates was conducted as described [32]. Twofold serial dilutions of sera and TNLs in PBS with $2 \mathrm{mM}$ EDTA, $0.1 \%$ Tween 20 and $0.1 \%$ bovine casein were applied to the ELISA plates including also reference sera/reference TNLs as well as negative controls. For detection of P. pneumotropica-specific serum-IgG, serum-IgG2c or TNL-IgA, plates were incubated for $1 \mathrm{~h}$ at RT with a 1:10,000 dilution of a HRP-conjugated goat anti-mouse IgG antibody (Jackson Immuno Research Laboratories), or a 1:10,000 dilution of a HRP-conjugated goat anti-mouse IgG2c antibody (Biorad; C57BL/6 mice only) or a 1:5000 dilution of HRP-conjugated goat anti-mouse IgA antibody (BIOMOL GmbH), respectively. ELISA plates were developed with 3,3',5,5'-tetramethylbenzidine as described [32].
Absorbance was measured at $450 \mathrm{~nm}$ (reference at $630 \mathrm{~nm})$.

The samples and the controls were measured in a duplicate series of four (seven for reference sera) twofold dilutions (starting with 1:200 for IgG and 1:50 for IgA). Sera collected from mice of a laboratory animal facility infected with the $R$. pneumotropicus strain JF4Ni were pooled and served as reference in the IgG and IgGc ELISA, TNL of an experimentally infected mouse from this experiment with a mean antibody titre as reference for the IgA ELISA. These reference samples were defined to include 100 ELISA units. Pooled sera and TNL samples from $R$. pneumotropicus-free mice were used as negative controls. Calculation of ELISA units for IgG and IgA was conducted as previously described [34].

\section{Determination of concentrations of IgG subtypes and} respective ratios in sera of experimentally infected mice Determination of IgG subtypes and calculation of respective ratios was conducted as described previously [32].

\section{Purification of DNA}

The DNeasy Blood \& Tissue Kit (Qiagen) was used according to the manufacturer's instruction to purify DNA from $R$. pneumotropicus and $R$. heylii cultures.

\section{PCR screening for RTX genes pnxIA, pnxIIA and pnxIIIA}

To detect the RTX toxin genes $p n x \mathrm{IA}, p n x \mathrm{IIA}$ and $p n x$ IIIA the primer pairs $p n x \mathrm{IAF} / p n x \mathrm{IAR}, p n x \mathrm{IIAF} /$ $p n x \mathrm{IIAR}$ and $p n x \mathrm{IIIAF} / p n x$ IIIARs (Additional file 6: Table S6) were used. The $p n x$ IA and $p n x$ IIA genes were amplified in full length from the DNA purified from different isolates (Additional file 3: Table S3), including strains genotyped in previous studies through 16S-23S rRNA internal transcribed spacer analysis [6, 35]. For detection of $p n x$ IIIA amplification of an internal $1 \mathrm{kbp}$ fragment was conducted. The $p n x$ sequences were amplified by PCR with 30 cycles and Taq-polymerase (Invitrogen Thermo Scientific Fisher) as recommended by the manufacturer using the following conditions: denaturation at $95{ }^{\circ} \mathrm{C}$ for $30 \mathrm{~s}$, annealing at $58^{\circ} \mathrm{C}$ (pnx IA and $p n x$ IIIA) or $61{ }^{\circ} \mathrm{C}$ (pnxIIA) for $30 \mathrm{~s}$ and elongation at $72{ }^{\circ} \mathrm{C}$ for $3: 30 \mathrm{~min}$ (pnxIA), 6:30 min (pnxIIA) or 2 min (pnxIIIA).

\section{Statistical analysis}

The Mann-Whitney test was performed to analyse differences between the different groups of mice. The Wilcoxon test was used for comparison of different time point values within the same group. The data in the Kaplan-Meyer survival and morbidity diagrams were analysed with the log rank test. Probabilities lower than 0.05 were considered significant, lower than 0.001 highly significant. 


\section{Additional files}

Additional file 1: Table S1. Scoring of semiquantitive bacteriological findings in $R$. pneumotropicus infected mice of the indicated strains succumbing to infection within the first week. (PDF $12 \mathrm{~kb}$ )

Additional file 2: Table S2. Scoring of semiquantitive bacteriological findings in R. pneumotropicus infected mice of the indicated strains surviving until the end of the observation period (4 weeks). (PDF $33 \mathrm{~kb}$ )

Additional file 3: Table S3. Scoring of clinical signs in mice infected with R. pneumotropicus. (PDF $10 \mathrm{~kb}$ )

Additional file 4: Table S4 $R$. pneumotropicus and $R$. heylii strains used in this study. (PDF $10 \mathrm{~kb}$ )

Additional file 5: Table S5 Scoring of catarrhal - purulent inflammations in mice infected with $R$. pneumotropicus. (PDF $4 \mathrm{~kb}$ )

Additional file 6: Table S6: Oligonucleotide primers used in this study. (PDF $16 \mathrm{~kb}$ )

\section{Abbreviations}

BGPST: 5\% BSA, 0.1\% gelatine and 0.05\% Tween20 in PBS; BHI: Brain heart infusion; CFU: Colony forming units; COB: Columbia Blood Agar; dpi: days post infection; ELISA: Enzyme-linked immunosorbent assay; FELASA: Federation of Laboratory Animal Science Association; IgG/A: Immune globuline G/A; IL: Interleukin; P. multocida: Pasteurella multocida P. pneumotropica: Pasteurella pneumotropica; PBS: Phosphate buffered saline; PCR: Polymerase chain reaction; $R$. pneumotropicus/heylii: Rodentibacter pneumotropicus/heylii; RTX: Repeats in toxin; SD: Standard deviation; Th: T-helper cell; TNL: Tracheonasal lavage

\section{Funding}

This work was financially supported by the European Funds of Regional Development (EFRE). The funding body had no role in the design of the study and collection, analysis, and interpretation of data as well as in writing the manuscript.

\section{Availability of data and materials}

The datasets analysed during this current study are available from the corresponding author upon a reasonable request.

\section{Authors' contributions}

$\mathrm{CB}$ and TG conceived the study. CB, TG, UM, WS, FF and RH designed the experiments. Acquisition of data was mainly conducted by JF. The clinica screenings were also performed by JK. LB provided strains, protocols and acquired data regarding strain differentiation. The histopathological screenings were performed by KK. Data analysis was conducted by JF with support from UM, FF, RH, WS and CB. JF and CB drafted the manuscript. All authors critically revised the manuscript, approved the final manuscript and agreed to be accountable for all aspects of the work.

\section{Ethics approval}

This animal study was registered and approved under no. TW 17/15 at the Provincial Head Office Saxony (Germany), Unit 24, Veterinary and Food Inspection (Landesdirektion Sachsen, Referat 24, Veterinärwesen und Lebensmittelüberwachung) which includes approval through the registered committee for animal experiments. This study and handling of mice in general was conducted in strict accordance with the principles outlined in the EU Directive 2010/63/EU and German Animal Protection Law.

\section{Competing interests}

GVG Diagnostics is a diagnostic services provider. Felix Fingas is part-time employee at GVG Diagnostics.

\section{Publisher's Note}

Springer Nature remains neutral with regard to jurisdictional claims in published maps and institutional affiliations.

\section{Author details}

'Institute for Bacteriology and Mycology, Faculty of Veterinary Medicine, University Leipzig, An den Tierkliniken 29, 04103 Leipzig, Germany.
${ }^{2}$ Fraunhofer Institute for Cell Therapy and Immunology, Leipzig, Germany. ${ }^{3}$ Institute for Veterinary Pathology, Faculty of Veterinary Medicine, University Leipzig, Leipzig, Germany. ${ }^{4}$ GVG Diagnostics GmbH, Leipzig, Germany. ${ }^{5}$ Institute of Bioanalytical Chemistry, Faculty of Chemistry and Mineralogy and Centre for Biotechnology and Biomedicine, University Leipzig, Leipzig, Germany. ${ }^{6}$ Central Unit for Animal Research and Animal Welfare Affairs, Heinrich-Heine-University, University Hospital, Düsseldorf, Germany. ${ }^{7}$ Institute of Immunology/Molecular Pathogenesis, Faculty of Veterinary Medicine and Centre for Biotechnology and Biomedicine, University Leipzig, Leipzig, Germany.

Received: 23 August 2017 Accepted: 15 May 2018

Published online: 30 May 2018

\section{References}

1. Boot R, Bisgaard M. Reclassification of 30 Pasteurellaceae strains isolated from rodents. Lab Anim. 1994;29:314-9.

2. Hedrich HJ. The laboratory mouse. 2nd ed; 2012.

3. Adhikary S, Nicklas W, Bisgaard M, Boot R, Kuhnert P, Waberschek T, et al. Rodentibacter gen. nov. including Rodentibacter pneumotropicus comb. nov., Rodentibacter heylii sp. nov., Rodentibacter myodis sp. nov., Rodentibacter ratti sp. nov., Rodentibacter heidelbergensis sp. nov., Rodentibacter trehalosifermentans sp. nov., Rode. Int J Syst Evol Microbiol. 2017;67:1793-806.

4. Dole VS, Banu LA, Fister RD, Nicklas W, Henderson KS. Assessment of rpoB and 165 rRNA genes as targets for PCR-based identification of Pasteurella pneumotropica. Comp Med. 2010;60:427-35.

5. Hayashimoto N, Ueno M, Takakura A, Itoh T. A specific polymerase chain reaction based on the gyrB gene sequence and subsequent restriction fragment length polymorphism analysis of Pasteurella pneumotropica isolates from laboratory mice. J Am Assoc Lab Anim Sci. 2007:46:54-8.

6. Benga L, Peter W, Benten M, Engelhardt E, Bleich A, Gougoula C, et al. Development of a multiplex PCR assay based on the 16S-23S rRNA internal transcribed spacer for the detection and identification of rodent Pasteurellaceae. J Microbiol Methods. 2013;95:256-61.

7. Sasaki $H$, Ishikawa $H$, Terayama $H$, Asano $R$, Kawamoto $E$, Ishibashi $H_{\text {, et al }}$ Identification of a virulence determinant that is conserved in the Jawetz and Heyl biotypes of Pasteurella pneumotropica. Pathog Dis. 2016;74:1-4

8. Sasaki H, Kawamoto E, Tanaka Y, Sawada T, Kunita S, Yagami Kl. Identification and characterization of hemolysin-like proteins similar to RTX toxin in Pasteurella pneumotropica. J Bacteriol. 2009;191:3698-705.

9. Sasaki H, Ishikawa H, Kojima K, Itoh M, Matsumoto T, Itoh T, et al. Intranasal immunization with a non-adjuvanted adhesive protein descended from Pasteurella pneumotropica and its preventive efficacy against opportunistic infection in mice. Vaccine. 2013:31:5729-35.

10. Sasaki H, Ishikawa $H$, Sato $T$, Sekiguchi $S$, Amao H, Kawamoto E, et al. Molecular and virulence characteristics of an outer membrane-associated RTX exoprotein in Pasteurella pneumotropica. BMC Microbiol. 2011;11:55.

11. Pritchett-Corning KR, Cosentino J, Clifford CB. Contemporary prevalence of infectious agents in laboratory mice and rats. Lab Anim. 2009:43:165-73.

12. Brennan PC, Fritz TE, Flynn RJ. Role of Pasteurella pneumotropica and Mycoplasma pulmonis in murine pneumonia. J Bacteriol. 1969;97:337-49.

13. Macy JD Jr, Weir EC, Compton SR, Shlomchik MJ, Brownstein DG, Macy JDJ, et al. Dual infection with Pneumocystis carinii and Pasteurella pneumotropica in B cell-deficient mice: diagnosis and therapy. Comp Med. 2000;50:49-55.

14. Baker DG. Natural pathogens of laboratory mice, rats, and rabbits and their effects on research. Clin Microbiol Rev. 1998;11:231-66.

15. Patten CC, Myles $\mathrm{MH}$, Franklin CL, Livingston RS. Perturbations in cytokine gene expression after inoculation of C57BL/6 mice with Pasteurella pneumotropica. Comp Med. 2010:60:18-24.

16. Mähler M, Berard M, Feinstein R, Gallagher A, Illgen-Wilcke B, PritchettCorning $\mathrm{K}$, et al. FELASA recommendations for the health monitoring of mouse, rat, hamster, guinea pig and rabbit colonies in breeding and experimental units. Lab Anim. 2014;48:178-92.

17. Bootz F, Kirschnek S, Nicklas W, Wyss S, Homberger F. Detection of Pasteurellaceae in rodents by polymerase chain reaction analysis. Lab Anim Sc. $1998: 48: 542-6$.

18. Boot R, Thuis HC, Veenema JL, Bakker RG. An enzyme-linked immunosorbent assay (ELISA) for monitoring rodent colonies for Pasteurella pneumotropica antibodies. Lab Anim. 1995;29:307-13.

19. Boot $R$, van de Berg L. Evaluation of antigen panels for ELISA monitoring of mouse colonies for antibodies to Pasteurellaceae. Lab Anim. 2006;40:194-9. 
20. Manning PJ, Gaibor J, Delong D, Gunther R. Enzyme-linked immunosorbent assay and immunoblot analysis of the immunoglobulin $\mathrm{G}$ response to whole-cell and lipooligosaccharide antigens of Pasteurella pneumotropica in laboratory mice with latent pasteurellosis. J Clin Microbiol. 1989:27:2190-4.

21. Scharmann W, Heller A. Survival and transmissibility of Pasteurella pneumotropica. Lab Anim. 2001;35:163-6.

22. Benga L, Benten WPM, Engelhardt E, Gougoula C, Schulze-Röbicke R, Sager M. Survival of bacteria of laboratory animal origin on cage bedding and inactivation by hydrogen peroxide vapour. Lab Anim. 2017;51:412-21.

23. Miller M, Ritter B, Zorn J, Brielmeier M. Exhaust air dust monitoring is superior to soiled bedding sentinels for the detection of Pasteurella pneumotropica in individually ventilated cage systems. J Am Assoc Lab Anim Sci. 2016;55:775-81.

24. Firacative $C$, Elisabeth AG, Schubert K, Schulze B, Müller U, Brombacher F, et al. Identification of Thelper ( Th ) 1- and Th2-associated antigens of Cryptococcus neoformans in a murine model of pulmonary infection. Sci Rep. 2018:8:1-14.

25. Martin R, Brady J, Lew A. The need for IgG2c specific antiserum when isotyping antibodies from C57BL/6 and NOD mice. J Immunol Methods. 1998;212:187-92.

26. See SB, Thomas WR. Protective anti-outer membrane protein immunity against Pasteurella pneumotropica infection of mice. Microbes Infect. 2013; 15:470-9.

27. Chapes SK, Mosier DA, Wright AD, Hart ML. MHCII, Trr4 and Nramp1 genes control host pulmonary resistance against the opportunistic bacterium Pasteurella pneumotropica. J Leukoc Biol. 2001;69:381-6.

28. Kawamoto E, Sasaki H, Okiyama E, Kanai T. Pathogenicity of Pasteurella pneumotropica in immunodeficient NOD / ShiJic- scid / Jcl and immunocompetent Crlj : CD1 ( ICR ) Mice. Exp Anim. 2011;60:463-70.

29. Hart ML, Mosier DA, Chapes SK. Toll-like receptor 4-positive macrophages protect mice from Pasteurella pneumotropica-induced pneumonia. Infect Immun. 2003;71:663-70,

30. Trunova GV, Makarova OV, Diatroptov ME, Bogdanova IM, Mikchailova LP, Abdulaeva SO. Morphofunctional characteristic of the immune system in BALB/C and C57BL/6 mice. Bull Exp Biol Med. 2011:151:112-5.

31. Germann T, Bongartz M, Dlugonska H, Hess H, Schmitt E, Kolbe L, et al. Interleukin-12 profoundly up-regulates the synthesis of antigen-specific complement-fixing $\lg \mathrm{G} 2 \mathrm{a}, \lg \mathrm{G} 2 \mathrm{~b}$ and $\lg \mathrm{G} 3$ antibody subclasses in vivo. Eur J Immunol. 1995;25:823-9.

32. Fornefett J, Krause J, Klose K, Fingas F, Hassert R, Eisenberg T, et al. Comparative analysis of clinics, pathologies and immune responses in BALB/C and C57BL/6J mice infected with Streptobacillus moniliformis. Microbes Infect. 2018;20:101-10.

33. Cockayne DA, Dunn PM, Zhong Y, Rong W, Hamilton SG, Knight GE, et al. $P 2 X_{2}$ knockout mice and $P 2 X_{2} / P 2 X_{3}$ double knockout mice reveal a role for the $\mathrm{P} 2 \mathrm{X}_{2}$ receptor subunit in mediating multiple sensory effects of ATP. J Physiol. 2005;5672:621-39.

34. Baums CG, Kock C, Beineke A, Bennecke K, Goethe R, Schröder C, et al. Streptococcus suis bacterin and subunit vaccine immunogenicities and protective efficacies against serotypes 2 and 9. Clin Vaccine Immunol. 2009; 16:200-8.

35. Benga L, Benten WP, Engelhardt E, Christensen H, Sager M. Analysis of 16S23S rRNA internal transcribed spacer regions in Pasteurellaceae isolated from laboratory rodents. J Microbiol Methods. 2012;90(3):342-9.

\section{Ready to submit your research? Choose BMC and benefit from:}

- fast, convenient online submission

- thorough peer review by experienced researchers in your field

- rapid publication on acceptance

- support for research data, including large and complex data types

- gold Open Access which fosters wider collaboration and increased citations

- maximum visibility for your research: over $100 \mathrm{M}$ website views per year

At BMC, research is always in progress.

Learn more biomedcentral.com/submissions 